\title{
Strategy of Nutrition Therapy for Infant's Primary Chylothorax, A Case Report
}

\author{
Suyun Li* and Yuan He \\ Department of Nutrition, China \\ *Corresponding author: Suyun Li, Department of Nutrition, China
}

\begin{tabular}{|c|c|}
\hline ARTICLE INFO & ABSTRACT \\
\hline Received: 蔧 May 09, 2019 & Citation: Suyun Li, Yuan He. Strategy of Nutrition Therapy for Infant's Primary \\
\hline Published: 蔧 May 16, 2019 & Chylothorax, A Case Report. Biomed J Sci \& Tech Res 18(1)-2019. BJSTR. MS.ID.003099. \\
\hline
\end{tabular}

\section{Introduction}

A male fetus has been found pleural effusion with right lung atelectasis as 20 week gestational age. At 36 week gestational age, the fetus has been delivered by caesarean. Birthweight is $3.4 \mathrm{Kg}$. The chest CT shows bilateral pulmonary consolidation with left pneumothorax. Abdomen ultrasound shown mild ascites. Ultrasonic cardiogram shown ductus arteriosus (PDA), and patent foramen ovale (PFO,2.6mm),pulmonary artery systolic pressure was $36 \mathrm{mmHg}$.

\section{Laboratory examination}

a) Biochemistry Test: HB 78g/L, ALT 133IU/L, AST

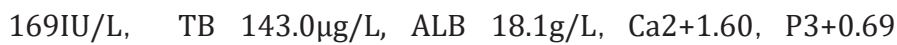
$\mathrm{mmol} / \mathrm{L}, \quad \mathrm{Mg} 2+0.72 \mathrm{mmol} / \mathrm{L}, \mathrm{K}+2.86 \mathrm{mmol} / \mathrm{L}$.

b) Hydrothorax : TG $13.4 \mathrm{mmol} /$ L Lymphocyte $80 \%$.

\section{Diagnosis}

Chylothorax, Newborn pneumonia, Bronchodysplasia, Hypercapnia, Severe neonatal asphyxia, Anemia, Neonatal persistent pulmonary hypertension, Pneumothorax(left), Cholestasis, Hypoproteinemia, Seroperitoneum

Electrolyte Disturbances: hypokalemia, hypocalcemia, hypomagnesemia, Hepatic injury, Premature large for gestational age infant (LGA), Infant of diabetic mother (IDMS).

\section{Clinical Treatment}

On the basis of clinical treatment such as pumped out $200 \mathrm{ml}$ yellow hydrothorax, limited fluid intake, atomized inhalation, liver protection therapy, anti-infection treatment, was given clinical nutrition treatment by specialized formula milk since 5-day-old.
The Strategy of Nutrition Treatment: The main purpose is to protect intestine's function, so in the first beginning of the treatment. Using a formula milk with low-calorie, low-albumen (mainly short chain polypeptide with mild whey protein) ,low-fat , mainly carbohydrate (maltodextrin) and vitamins, feeding this patient to restart the intestine from $3-5 \mathrm{ml}$ per times, $0.6 \mathrm{kcal} / \mathrm{ml}$, gradually increase to $0.8 \mathrm{kcal} / \mathrm{ml}$, the total energy meets over $60 \%$ of the basic nutrient requirements. The albumen (mainly whey protein, starts from $1.0-2.0 \mathrm{~g} / \mathrm{d}$ ) and MCT (starts from $0.5 \mathrm{~g} / \mathrm{d}$ ) also were added to this formula.

\section{Result and Discussion}

After taking closed thoracic drainage for 47days, drainage catheter has been removed for the left pneumothorax disappeared. 66 day-old, chest CT shown a small amount of effusion in the left chest, abdomen effusion was gone. The patient recover energetic, with low limbs power, weight was $3.85 \mathrm{~kg}$, length was $57 \mathrm{~cm}$, Feeding volume was added to $70 \mathrm{ml} /$ time, 8 times/day, defecate 1-2 times/day with yellow paste. Laboratory tests showed HB 92g/L, ALT 151IU/L, AST 180IU/L, TB 6.8 $\mu \mathrm{g} / \mathrm{L}$, ALB $38 \mathrm{~g} / \mathrm{L} \mathrm{a} 2+1.22 \mathrm{mmol} / \mathrm{L}, \quad \mathrm{K}+4.79 \mathrm{mmol} /$. At present, the child is 12 months old, $77 \mathrm{~cm}$ in height, $8.5 \mathrm{Kg}$ in weight, in good mental condition, sensitive, normal limb strength, without chest and abdominal effusion, able to crawl with hands and knees and can stand holding something. HB 136g/L, ALB 41g/Land the defecate is same as before.

Clinical nutritional treatment is always as main therapeutic method of primary chylothorax, mainly by using MCT replaces 
LCT in the diet $[1,2]$. But the intestinal insufficiency are always overlooked $[3,4]$. For infants with primary chylothorax, intestine is the most vulnerable organ [5], which also become the main restriction for the efficiency of nutrition. The cause of infantile primary chylothorax remains unclear, but prolonged parenteral nutrition and improper enteral nutrition will definitely jeopardize the intestine function and its development, thus, trigger functional and organic damage of the gastrointestinal tract [6]. Thus, in the process of nutritional treatment, good tolerance that based on not increasing digest burden is much more important than only focus on calorie and nutrients [7]. Only taking sufficient energy and nutrients into consideration and ignore the status of intestine function, the mild enteral nutrition and the normal form of nutrients can be a huge burden for the relatively weak or already damaged intestine, and turning nutrition into a huge blow to intestine function and might even totally ruin the digestive system. So we adjust the formula milk and the feeding volume, by which gradually increase the tolerance of digestive system and stimulus development of newborn patient' digestive and absorptive ability.

ISSN: 2574-1241

DOI: 10.26717/BJSTR.2019.18.003099

Suyun Li. Biomed J Sci \& Tech Res

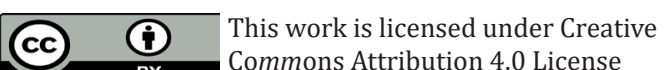

Submission Link: https://biomedres.us/submit-manuscript.php
Warming adjusting nutrition therapy formula according to patients intestinal function is a key principle of clinical treatment.

\section{References}

1. Lee J, Kong MS (2008) Primary intestinal lymphangiectasia diagnosed by endoscopy following the intake of a high-fat meal. Eur J Pediatr 167(2): 237-239.

2. Lai Y, Yu T, Qiao XY, Zhao LN, Chen QK (2013) Primary intestinal lymphangiectasia diagnosed by double-balloon enteroscopy and treated by medium-chain triglycerides: a case report. J Med Case Rep 7: 19.

3. Bengtsson BO (2014) Outcome of neonatal chylous effusions: what do you tell the parents? A 10-year experience in a community hospital. Am J Perinatol 31(12): 1037-1042.

4. Bellini C, Ergaz Z, Radicioni M, Forner Cordero I, Witte M, et al. (2012) Congenital fetal and neonatal visceral chylous effusions: neonatal chylothorax and chylous ascites revisited. A multicenter retrospective study. Lymphology 45(3): 91-102.

5. CE Commare, KA Tappenden (2007) Development of the Infant Intestine: Implications for Nutrition Support. Nutrition in Clinical Practice 22(2): 159-173.

6. Suyun Li, Xiaoqian Liu, Yuan He, Li Q Ji L, et al. (2017) Nutritional therapy and effect assessment of infants with primary intestinal lymphangiectasia. Medicine 96(51): 1-6.

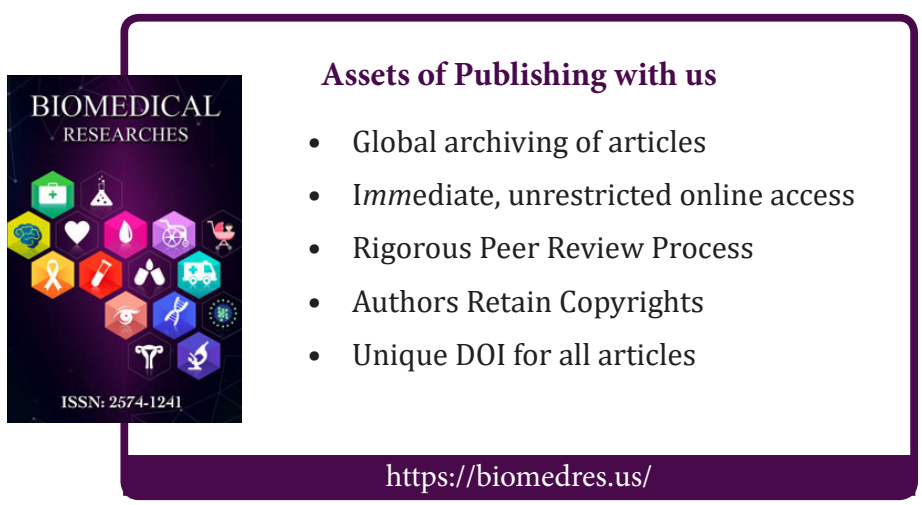

